\title{
A A New Validation Approach of a New Three-Phase High Voltage Power Supply for Microwaves Generators with one Magnetron by Phase
}

\author{
M. Bassoui*, M. Ferfra*, M. Chraygane** \\ * Research team in power and control EMI, Mohamed -V University, Rabat, Morocco \\ ** MSTI Laboratory, EST Ibn Zohr University, Agadir-Morocco University, Morocco
}

\begin{tabular}{l} 
Article Info \\
\hline Article history: \\
Received Jun 9, 2015 \\
Revised Oct 25, 2015 \\
Accepted Nov 16, 2015 \\
\hline
\end{tabular}

Keyword:

Instantaneous power

Performance

Power factor

Power supply

Three-phase transformer

\begin{abstract}
In order to validating the new three-phase High voltage power supply for microwave generators with one magnetron by phase, this paper presents a new validation approach to evaluate the proposed model with several evaluations. This approach is based on the calculation and measurement of the performance and the power factor of this new three-phase power supply, also the study of the operation of this new system in case of failure. The design of this power supply is composed of new three-phase transformer with magnetic shunt, supplying by phase a voltage doubler cell composed of a capacitor and a diode. Each cell in turn, supplies a single magnetron. In this paper we have presented the new three-phase transformer by its equivalent model; it's a $\pi$ quadruple model composed of storable inductances able to translating the nonlinear saturation phenomena for stabilization of the magnetron current. The voltage and current curves obtained by simulation with MATLAB SIMULINK are in good conformity with those obtained by experimental of conventional power supply using a single phase transformer for one magnetron. The same curves will allow us to plot the instantaneous power absorbed by each magnetron. This leads to determine the average power emitted by each magnetron, and establish the balance of the power microwave generator by computing its performance which is compared to that obtained from experimental. After that we will compute the power factor of this power supply and we will study its operation in case of failure of one or two magnetrons.
\end{abstract}

Copyright (C) 2016 Institute of Advanced Engineering and Science. All rights reserved.

\section{Corresponding Author:}

Mohamed Bassoui,

Departement of Electrical Engineering,

MOHAMED-V University,

Mohammadia school of enginerinrs Rabat.Morocco

Email: bassouimohamed@gmail.com

\section{INTRODUCTION}

Currently, to supply one magnetron, the current single-phase power supply of the tube microwave generator uses a single-phase transformer with magnetic shunts by magnetron [2-12]. To contribute to the development of the technological innovation in the manufacturing industry of the power supply for magnetrons, this work is part of the development and validation of a new type of HV power supply with a three-phase character for one magnetron by phase. Figure 1 shows the setup of the new three-phase high voltage power supply of microwaves generators with one magnetron by phase. This scheme is composed of a new three-phase transformer, supplying by phase a cell doublers composed of capacitor and a diode, each cell supplies at its output a single magnetron. The new three-phase magnetic leakage transformer, not yet manufactured, is the basic element of this new power supply. This special three-phase transformer with 
magnetic shunts ensures the stabilization of the anodic current in each magnetron thanks to the saturation of its magnetic circuit. Compared to the conventional transformer, the leakage flux in the shunt is of the same order as both the primary and secondary fluxes. Thus, the theory of classical transformers does not apply in the case of the transformer with shunts. [1]

The aim of this article is to validate under MATLAB SIMULINK the proposed model with several evaluations. The paper is organized as follows: on the first step we presented the equivalent model of a new three-phase transformer. This model will be integrated in overall scheme of the power supply to be suitable for the modeling of the whole device, using numerical simulation software MATLAB SIMULINK code. The voltage and current curves obtained by simulation compared with those obtained experimentally by a conventional power supply using a single-phase transformer for one magnetron [2-12]. In the second step we study the power balance of this new three-phase power supply by determining the value of the instantaneous power curve, this lead to establish the average power emitted by each magnetron, then we will establish the energetic balance of the power microwave generator by computing their performance that must be identical to that obtained experimental y. Next we will compute the power factor of this new three-phase power supply. Finally we will study the possibility of the functioning of this new system in case of breakdown of one or two magnetrons.
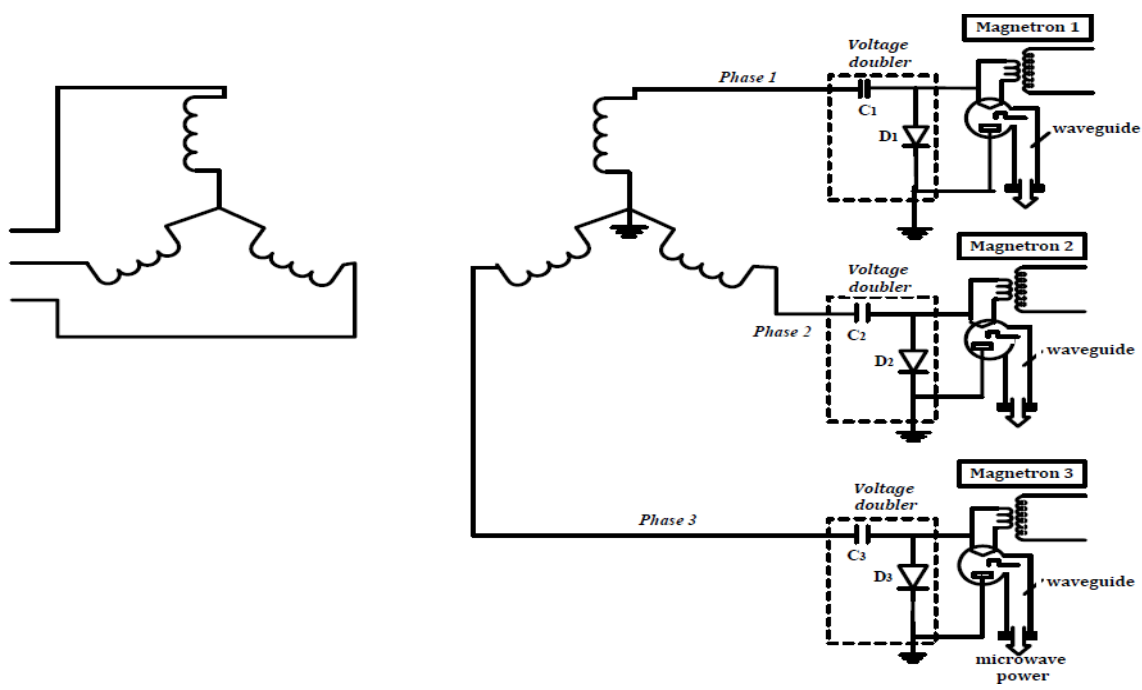

Figure 1. Three-phase power supply for magnetron by phase

\section{MODELING OF THE NEW THREE-PHASE POWER SUPPLY WITH ONE MAGNETRON}

\subsection{Description of the New Three-Phase Transformer with Shunts}

In our design of this new three-phase transformer with magnetic shunt, we use an armored structure tetrahedron type (Figure 2) to represent the equivalent magnetic circuit of the transformer, which will undoubtedly allow to reduce the congestion and the volume of this new device and makes it more economical. This structure of the new three-phase transformer with shunts, not yet manufactured, that will be used in the HV power supplies for $\mathrm{N}$ magnetrons per phase (treated case: $\mathrm{N}=1$ magnetron per phase). The magnetic shunt serves to divert an important part of flux circulating between the primary and secondary windings of each phase. 


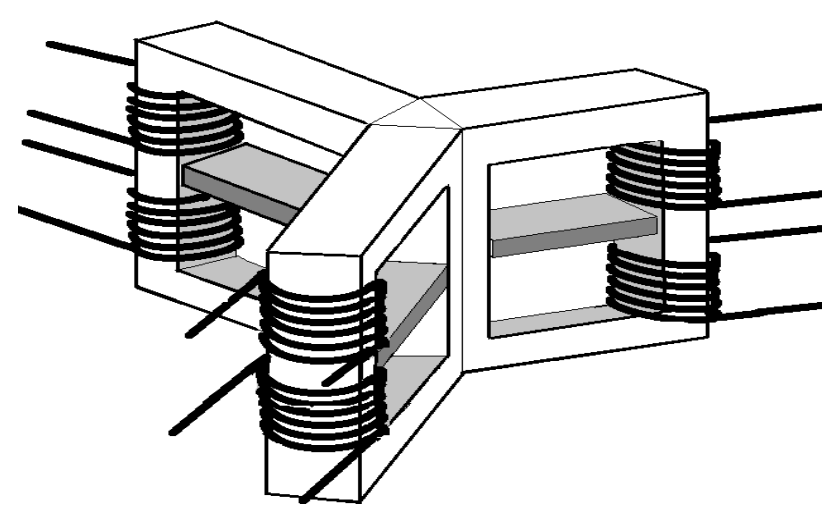

Figure 2. Diagram of the equivalent magnetic circuit of the new three-phase transformer with magnetic shunt

\subsection{Electrical and Magnetic Equations}

In the proposed study, we consider the new three-phase transformer without iron losses (hysteresis loss and eddy current). And to simplify the study, we consider the Star Star (Yy) coupling between the primary and secondary windings. By the application of Ohm's generalized law to the primary windings (receiver convention) and secondary ones (generator convention) and the Hopkinson's law, we obtain the following complete electric and magnetic equations governing the operating of the three-phase transformer. To simplify the study we take the phase A as example:

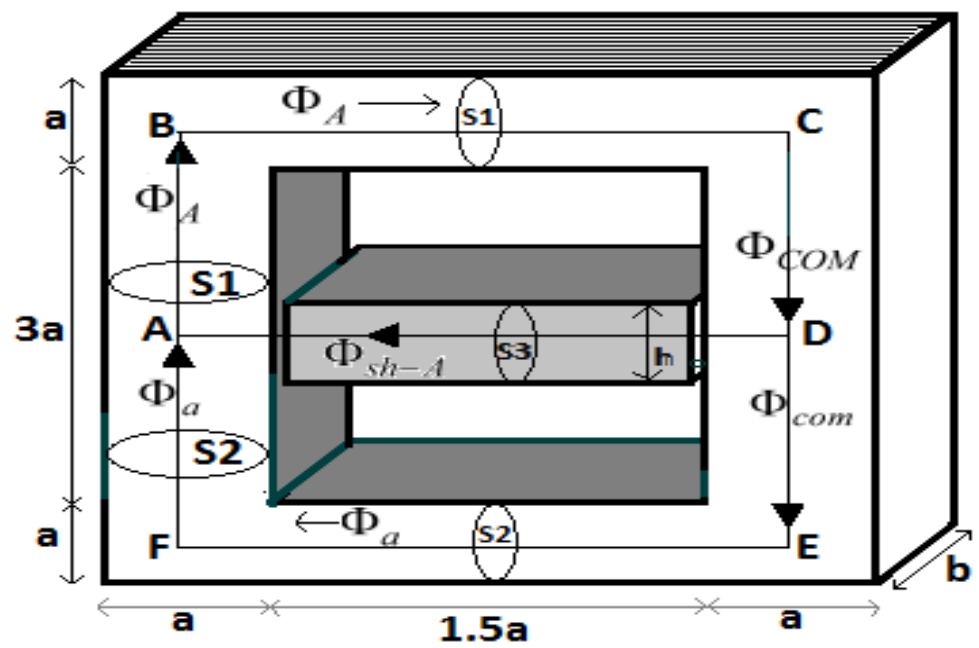

Figure 3. Diagram of the equivalent magnetic circuit of the new transformer (Phase A as example)

* Electric equations

$$
\begin{aligned}
& U_{\mathrm{A}}=r_{A} \cdot i_{A}+n_{1} \cdot \frac{\partial \Phi_{A}}{\partial t} \\
& U_{a}=-r_{a} \cdot i_{a}+n_{2} \cdot \frac{\partial \Phi_{a}}{\partial t}
\end{aligned}
$$


* Magnetic equations

$$
\begin{aligned}
& R_{A} \Phi_{A}+R_{s h-A} \cdot \Phi_{s h-A}=n_{1} \cdot i_{A} \\
& -R_{s h-A} \cdot \Phi_{s h-A}+R_{a} \cdot \Phi_{a}=-n_{2} \cdot i_{a} \\
& R_{A} \cdot \Phi_{A}+R_{a} \cdot \Phi_{a}=n_{1} \cdot i_{A}-n_{2} \cdot i_{a} \\
& \Phi_{A}=\Phi_{a}+\Phi_{s h-A}
\end{aligned}
$$

By transforming the equations (1) to (7), we obtain the following equations (8) to (13) gouverning the operation of the $\pi$ quadruple model [13]-[14] representative of the transformer refered to secondary (For more details see [15]-[16]).

$$
\begin{aligned}
& U_{A}^{\prime}=r_{A}^{\prime} \cdot i_{A}^{\prime}+\frac{\partial}{\partial t}\left(L_{p-A}^{\prime} \cdot i_{p-A}^{\prime}\right) \\
& U_{a}=-r_{a} \cdot i_{a}+\frac{\partial}{\partial t}\left(L_{s-a} \cdot i_{s-a}\right) \\
& n_{2} \cdot \frac{\partial \Phi_{A}}{\partial t}=\frac{\partial}{\partial t}\left(L_{s-a} \cdot i_{s-a}\right)+\frac{\partial}{\partial t}\left(L_{s h-A}^{\prime} i_{s h-A}^{\prime}\right) \\
& i_{A}^{\prime}=i_{p-A}^{\prime}+i_{s h-A}^{\prime} \\
& i_{s-a}=i_{s h-A}^{\prime}+i_{a} \\
& \left.n_{2} \cdot \Phi_{s h-A}=\left(L^{\prime}{ }_{s h-A}\right)^{f} *\left(i^{\prime}{ }_{s h-A}\right)^{f}+\left(L^{\prime}{ }_{s h-A}\right)^{e} *\left(i^{\prime}{ }_{s h-A}\right)^{e}\right)
\end{aligned}
$$

The previous equations respond to the equivalent digram of the first phase A of the new three-phase transformer. Thus we obtain a $\pi$ model of this transformer composed of three nonlinear inductances referred to secondary, $\mathrm{L}_{\mathrm{p}-\mathrm{A}}$ on the primary side, $\mathrm{L}_{\mathrm{s}-\mathrm{A}}$ on the secondary side and $\mathrm{L}_{\text {Sh-A }}$ on the shunts side (Figure 3).

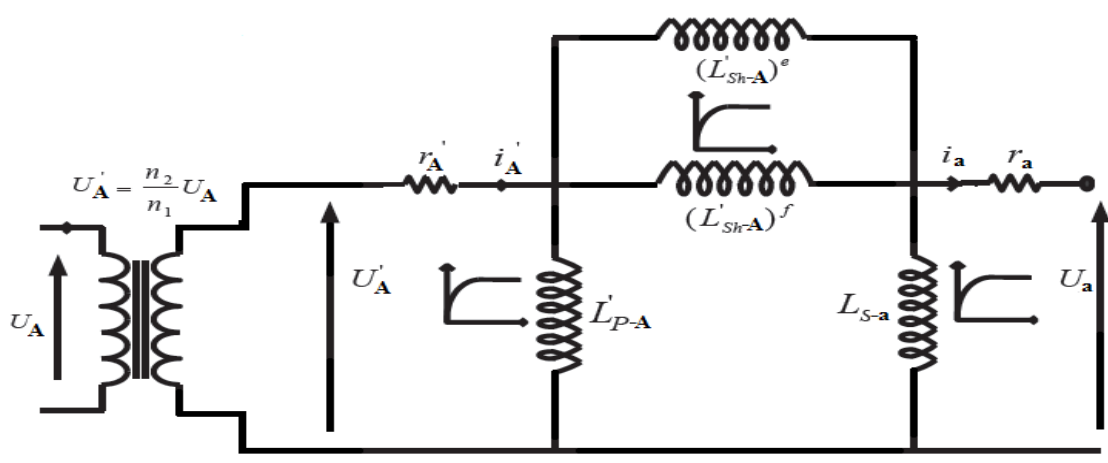

Figure 4. New quadruple model of three-phase transformer with shunts

By perfectly similar calculations, the equation system which responds to the equivalent diagram of the phase $\mathrm{B}$ and $\mathrm{C}$ permits to find the models indicated on the Figure 5. The equivalent circuit should reflect the behavior of the total power supply including the magnetron and the transformer with shunts. 


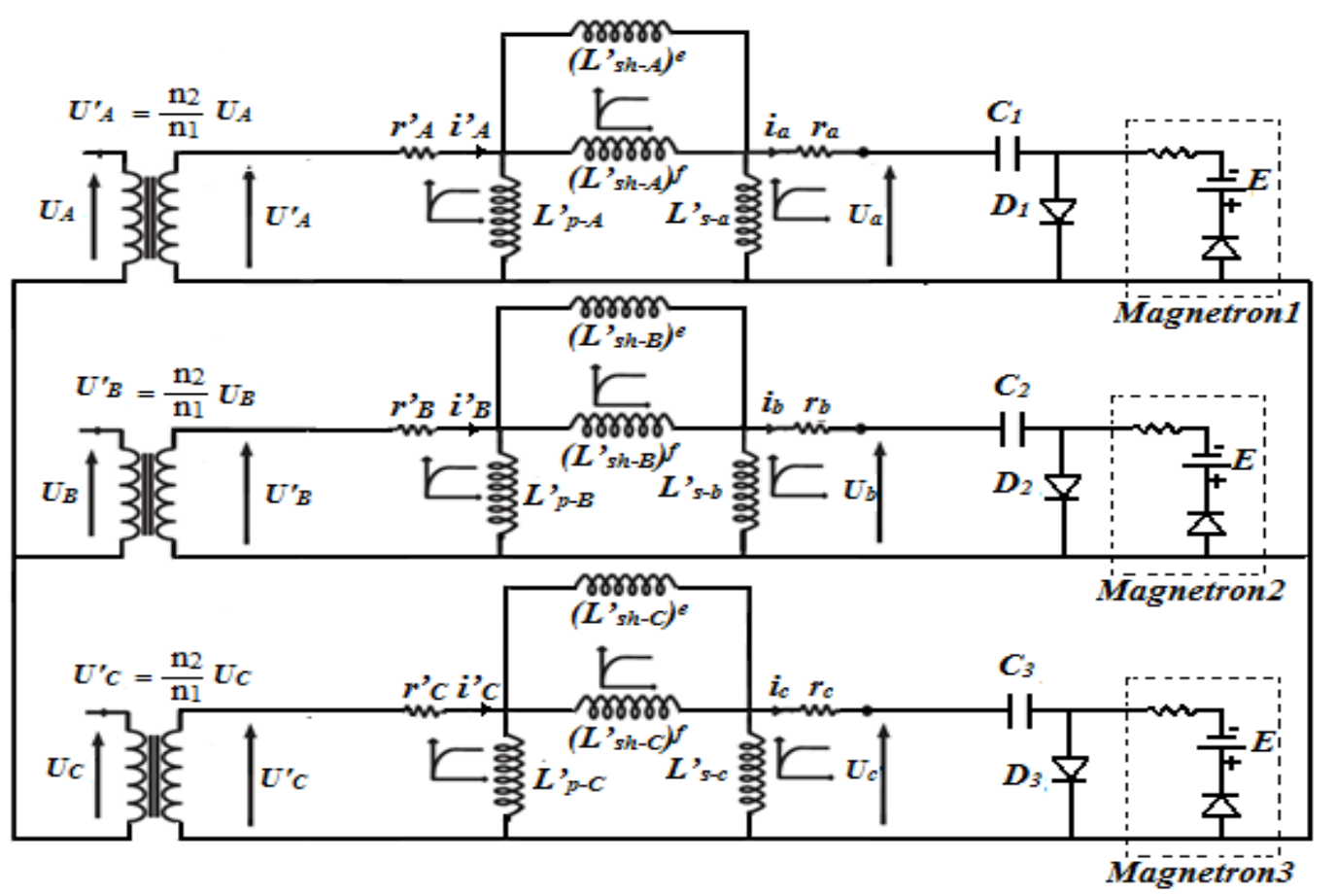

Figure 5. Modeling of the new three-phase transformer with magnetic shunts using MATLAB SIMULINK code

\subsection{Simulation with Matlab - Simulink of the Nominal Functioning of the Three-Phase Power Supply}

To validate this model we have integrated the model of the new transformer in the high voltage power supply circuit from the source to the magnetrons Each magnetron is represented by an equivalent diagram deduced from its electrical characteristics which is formally similar to that of a diode with dynamic resistance $\mathrm{R}=350 \mathrm{Ohms}$ and threshold voltage $\mathrm{E}=3800$ Volts. The nonlinear inductors studied in Figure 5 depend on the reluctance of the magnetic circuit portion with a section $\mathrm{S}$ and average length 1 . The implementation of each nonlinear inductance with its analytic expressions under MATLAB-SIMULINK software was realized by using the blocks shown in Figure 6 [14].

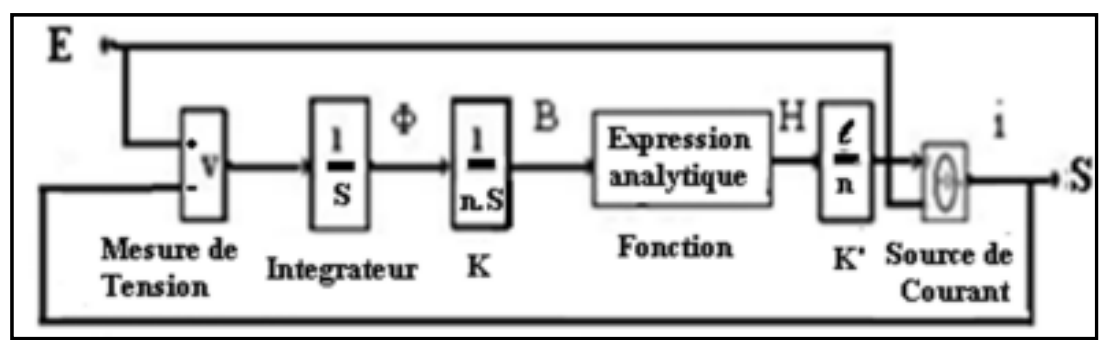

Figure 6. Implementation of each nonlinear inductance under MATLAB-SIMULINK

We validate this model by comparing simulation results (Figure 7) with those obtained from tests already carried out [2]-[3]-[13] of conventional power supply using a single phase transformer for one magnetron (Figure 8). The simulation of the proposed system is carried out on the MATLAB version 7.10.0 (2010a) using the sim power system (SPS) toolbox and discrete step solver of 1e-5. 

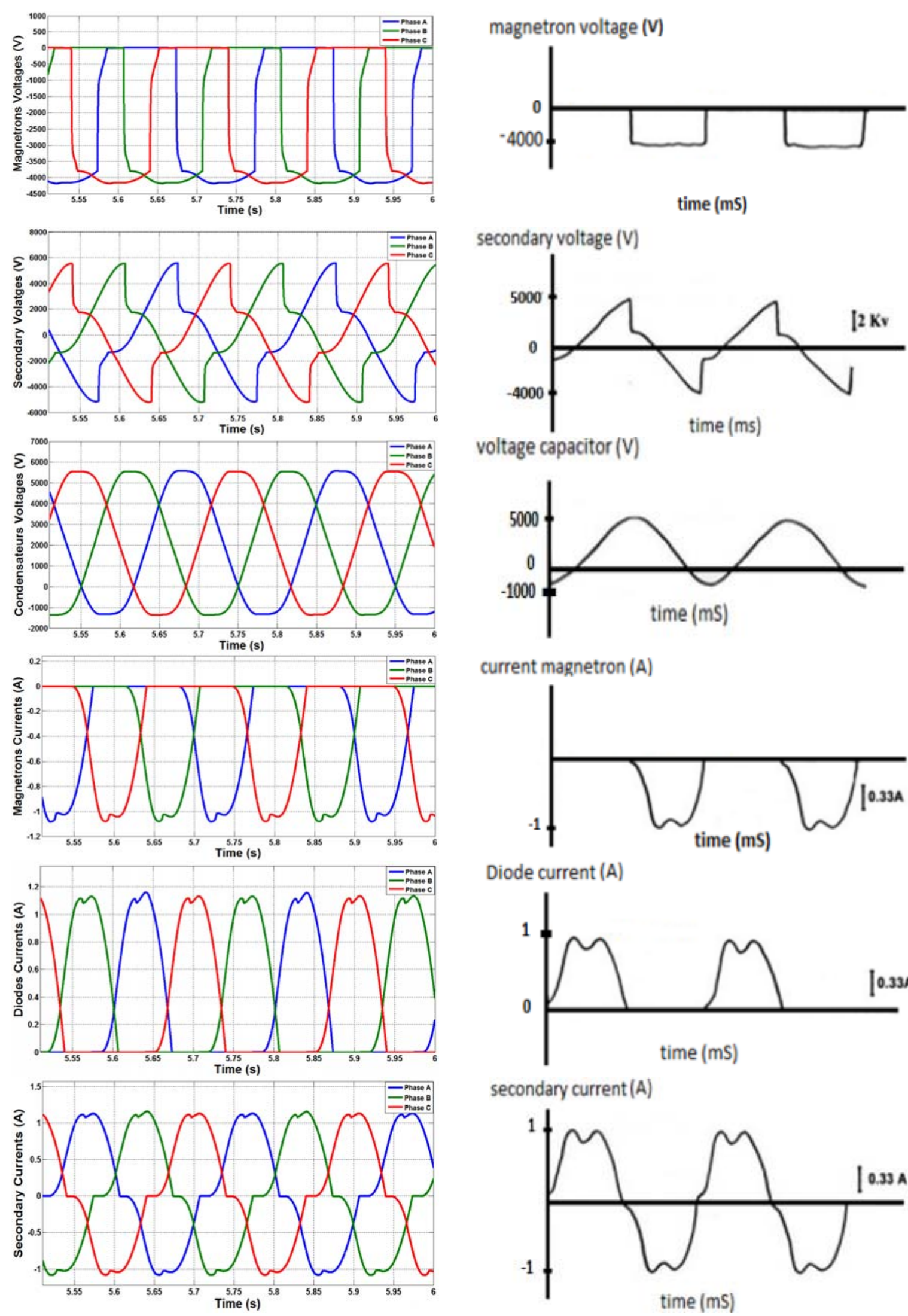

Figure 7. Simulation with MATLAB SIMULINK: Forms of currents and voltages waves

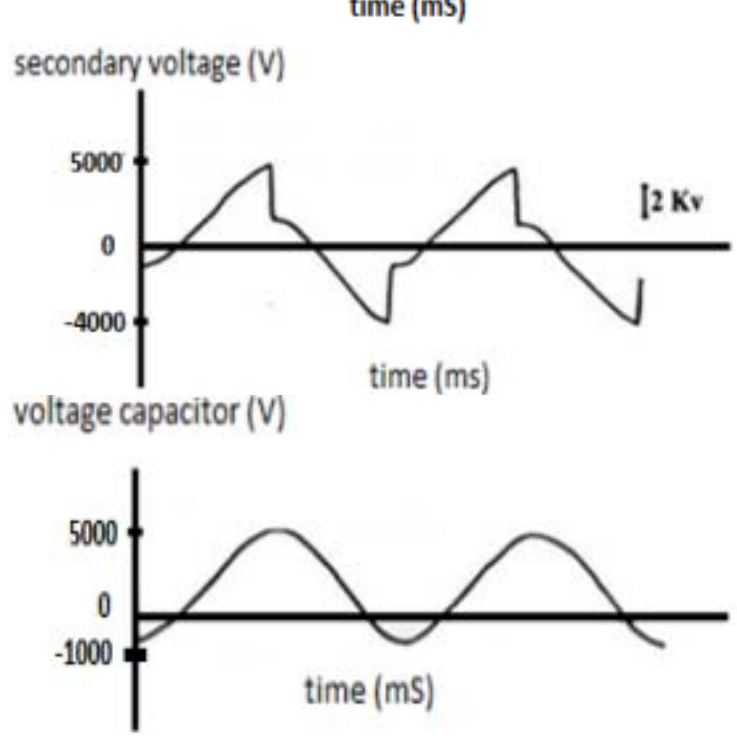

current magnetron (A)

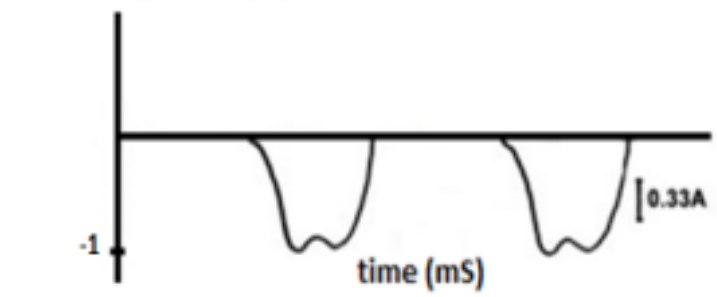

Diode current (A)

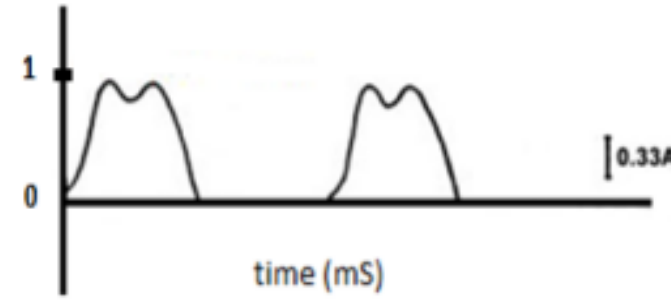

secondary current (A)

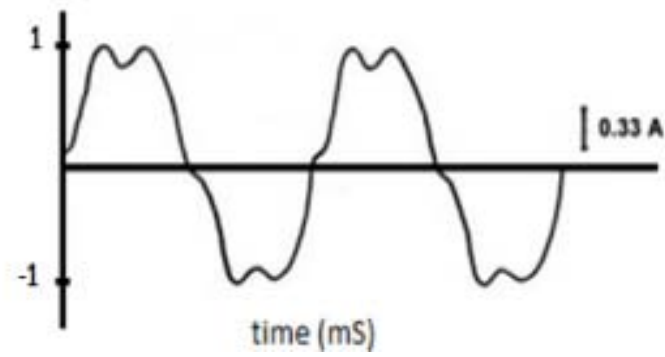

Figure 8. Experimentals forms of currents and voltages waves of conventional power supply using a single phase transformer for one magnetron [2] 
The electrical signal obtained (voltages and currents) from simulation with MATLAB SIMULINK are curves of various sizes, periodic, non-sinusoidal and dephasing by $(2 \pi / 3)$ between them. These signals have the same form as those of experimental and simulated of conventional power supply using a single phase transformer for one magnetron, in particular, the maximum value of the magnetron current which respect the constraint imposed by the manufacturer of the magntegtron $\left(\mathrm{I}_{\max }<1.2\right.$ A).

\section{VALIDATION OF THE NEW MODEL OF THE NEW POWER SUPPLY UNDER MATLAB SIMULINK}

\subsection{Energy Balance of the New Three-Phase Power Supply and its Performance}

\subsubsection{Research Method}

Power is one of the most important quantities of electricity. It describes the energy requirements of a system. During this work, we will validate the nominal functioning of this new three-phase power supply by computing the instantaneous power curves of each magnetron, this lead to establish the average power of each magnetron (Figure 9). This indicates that the transformer delivers an average power equal to 3821 watts. That is to say there will be 1273 watts for each magnetron. Witch confirms full power operation of the new three-phase power supply with one magnetron by phase. The curves obtained by simulation with MATLAB SIMULINK code are the same forms of that obtained by experimental of a conventional power supply using a single phase transformer with magnetic shunt (Figure 10) [17]-[18].

\subsubsection{Results and Comparisons}

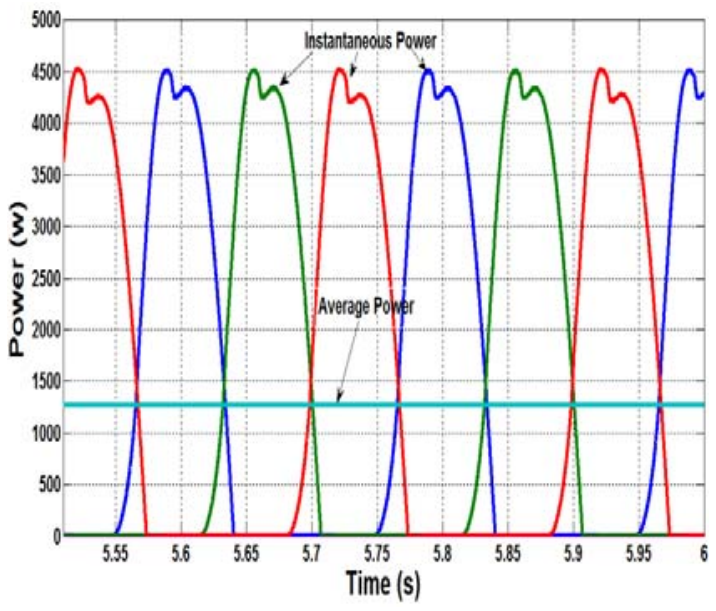

Figure 9. Average power and instantaneous power obtained by Matlab-Simulink for a three-phase power supply

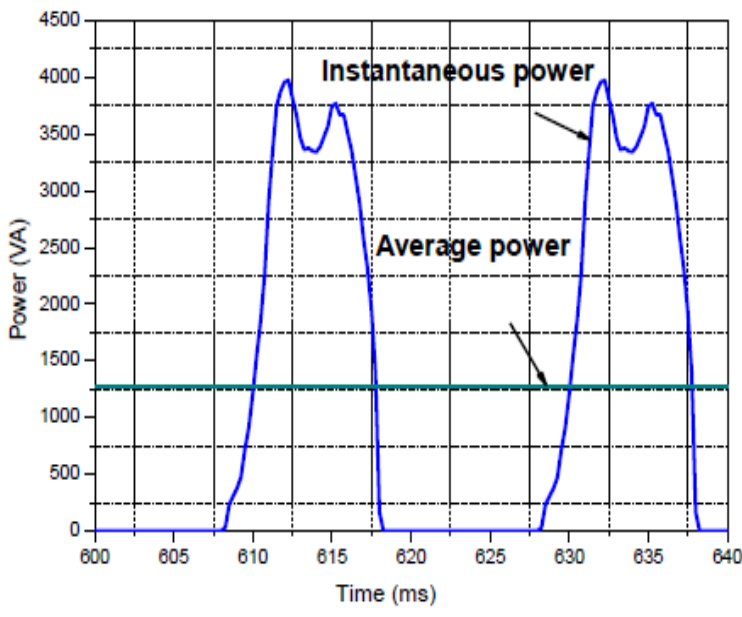

Figure 10. Average power and instantaneous power obtained by experimental of a single-phase power supply [17]

From the curves of power obtained, we can therafater deduce the performance of this new threephase power supply which is $92 \%$, namely and $93 \%$ experimental, either. We note that the namplate of the single phase transformer indicate an apparente power on the order $1650 \mathrm{~V}$ with a factor of primary power 0.825 .

$$
\begin{aligned}
& \eta_{\text {Matlab-simulnik }}=\frac{\mathrm{P}_{\mathrm{s}}}{\mathrm{P}_{\mathrm{e}}}=\frac{3821}{4142}=0.92 \\
& \eta_{\text {Experimental }}=\frac{1275}{1650 * 0.825}=0.93
\end{aligned}
$$


We see that the performance obtained by MATLAB SIMUINK coresponding to the new three-phase power supply is identical to that obtained from experimental of a conventional power suply using a single phase transformer for one magnetron.

\subsection{Power Factor of the New Three-Phase Transformer}

\subsubsection{Research Method}

During recent years the increase in reactive power consumption in electrical distribution systems has emerged a new term that is the power factor (PF). This term is used to express how effectively the electrical energy is converted into useful form and indicating the quality of the service to the electricity authorized and end-users. Power factor is the ratio between the active (P) and the apparent (S) powers. It is also defined as the cosine value of the Phase Difference (PD) between the voltage (V) and current (I) of an AC electrical power system. Power factor is a very important parameter in power electronics because it gives a measure of how effective the real power utilization in the system is. In order to measure the power factor, we use the formula: [19]-[20]

$$
\mathrm{PF}=\cos \varphi=\frac{\mathrm{P}}{\mathrm{S}}
$$

where $\varphi$ is the angle value of the phase difference between the voltage and the current signals.

The Measurement of the Power Factor of this three-phase transformer under Matlab Simulink is performed using SimPowerSystems library. We calculate active power, apparent power and power factor using the following blocks (Figure 11).

- Mean: This block calculates the average value of the instantaneous power in consequence deduct the active power.

- $\quad$ Rms: This block calculates the rms of current and voltage.

In this case, the three-phase system is considered with load balancing. Therefore we calculated:

- The Active power as the average value of $v_{a} i_{a}+v_{b} i_{b}+v_{c} i_{c}$

- The Apparent power $S=\mathrm{V}_{\mathrm{a}} \mathrm{I}_{\mathrm{a}}+\mathrm{V}_{\mathrm{b}} \mathrm{I}_{\mathrm{b}}+\mathrm{V}_{\mathrm{c}} \mathrm{I}_{\mathrm{c}}$

- $\quad$ The Power factor $P F=\frac{\mathrm{P}}{\mathrm{S}}$

\subsubsection{Results and Discussion}

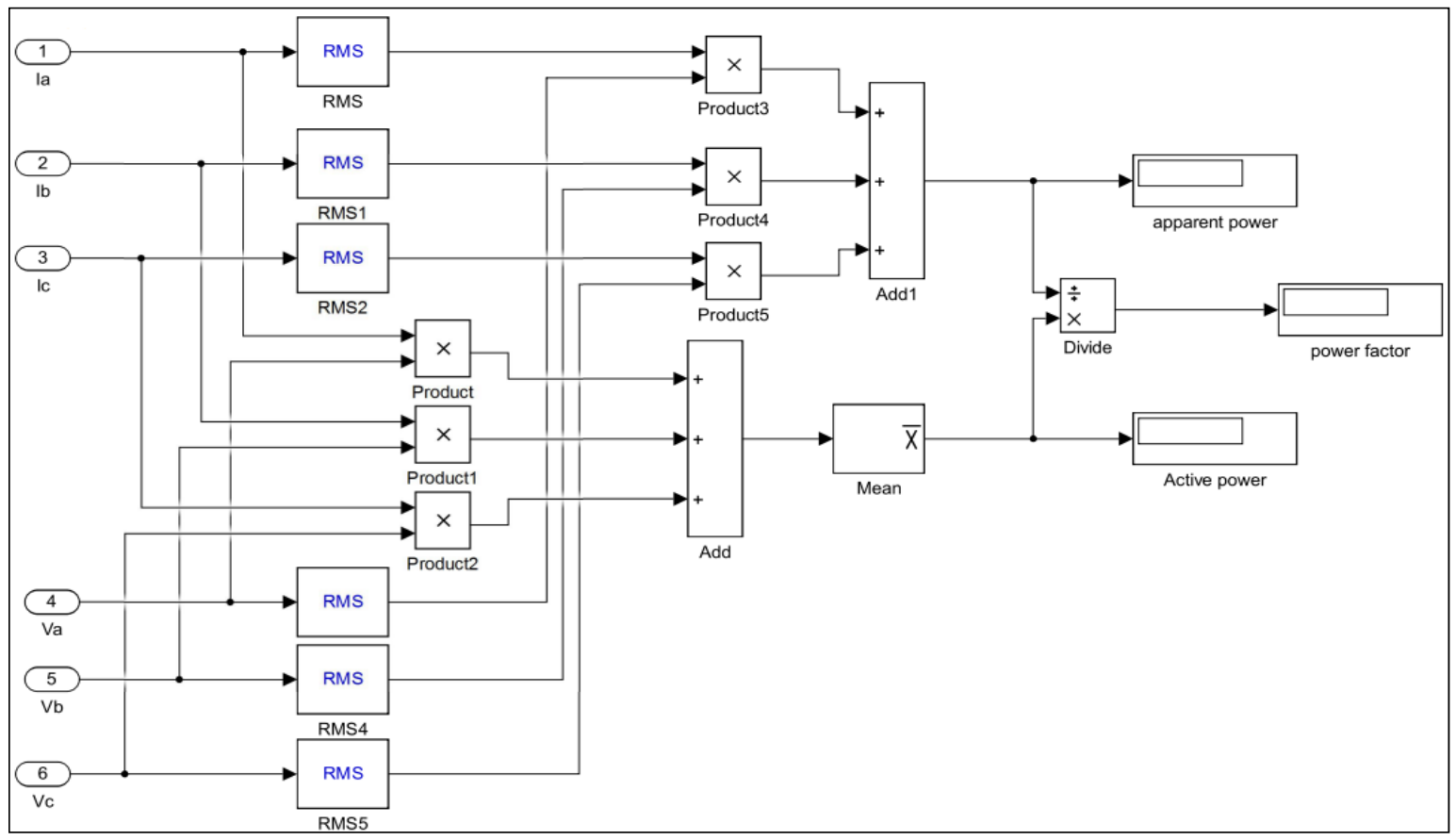

Figure 11. Diagram block of power factor measurement 
The simulation results of PF calculated by proposed method are indicate that the power factor of this transformer is on the order of 0.89 , meaning $89 \%$ of the power is being used for useful work.

\subsection{Verfication of the Operation of the New Three-Phase Power Supply in Case of Failure}

\subsubsection{Research Method}

The study of the operation of the three magnetrons in normal operation is performed. Now we are going to study the case where any of the three magnetrons fails to envisage the influence of the failure magnetron on the operation of the remaining magnetrons. To do this we will repeat the simulation and we observe the waveforms of currents and voltages by using MATLAB SIMULINK code. Figure 12 shows the waveforms of currents and voltages obtained from this simulation.

\subsubsection{Results and Discussion}
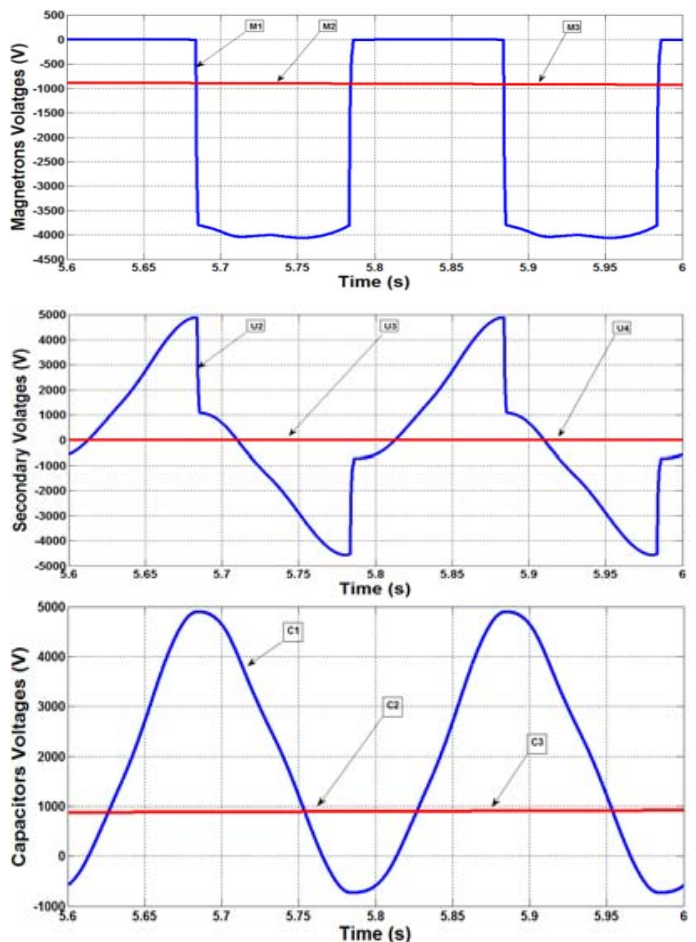
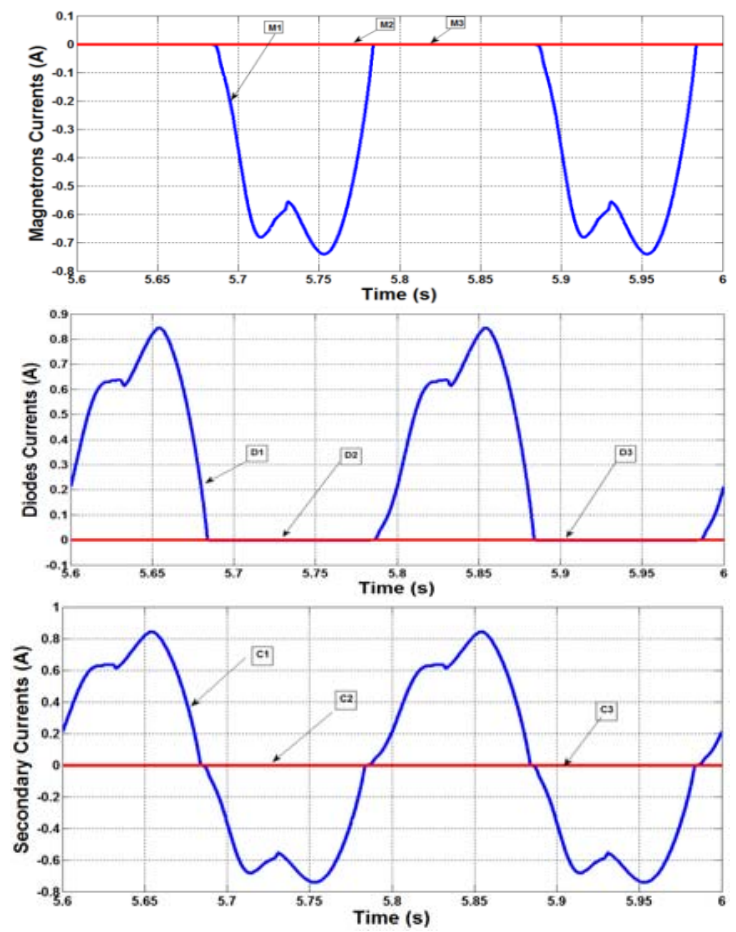

Figure 12. Simulation results of the new power system in the non linear mode with the MATLAB SIMULINK code (M2 \& M3 off)

From the Figure 12 we see that the functioning of this new system in case of breakdown of two magnetrons is performed. The signals obtained from this simulation are identical to those in normal operation (without fail). This confirms that the failure of one or two magnetron does not affect the operation of the remaining magnetron it suffices to replace the magnetron off by o new one.

\section{CONCLUSION}

In this paper, we proposed a validation approach of a new three-phase power supply for microwave generator by computing their performance which is identical to that obtained from experimental for a conventional power supply using a single phase transformer for one magnetron. In our research, we have also computing the power factor of this new three-phase transformer. On the other hand the failure of one or two magnetron does not affect the operation of the remaining magnetron.

For industrial applications, The encouraging and the satisfying results obtained during this validation approach; will certainly encourage us to realize the new three-phase transformer with magnetic 
shunts for a new generation of industrial microwaves generators. This will contribute to the technological innovation.

As perspectives, this work can be extended for the study of the energetic balance of new three-phase or six-phase power supply for several magnetrons by phase.

\section{APPENDIX}

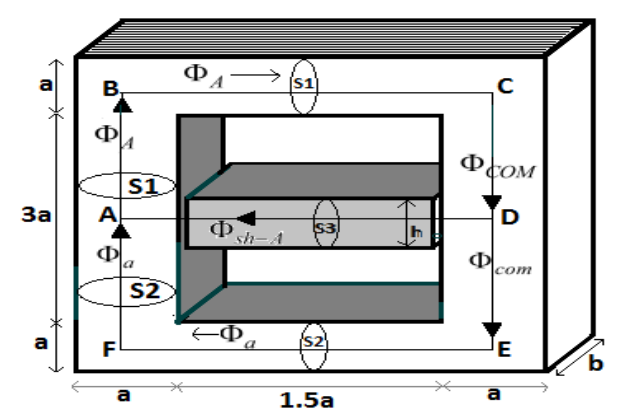

Figure 13. Geometry of transformer with magnetic shunt (Phase A as example)

During this work, we have taken as reference the following geometrical dimensions of the threephase transformer HV with magnetic shunts:

- The width of the non-wound core: $\mathrm{a}=25 \mathrm{~mm}$

- The width of the magnetic circuit: $b=120 \mathrm{~mm}$

- Number of stacked sheets of the shunt: $\mathrm{n} 3=18$

- Number of turns in the primary: $n 1=224$

- Number of secondary turns: n2 $=2400$

- Height of the sheet stack of shunts: $h=0.5 \mathrm{n} 3$.

- $\quad$ Surface of the core: $\mathrm{S} 1=\mathrm{S} 2=\mathrm{a} . \mathrm{b}$

- $\quad$ Surface of shunt: S3 =h.b

- Thickness of the air gap: $\mathrm{e}=0.75 \mathrm{~mm}$

\section{REFERENCES}

[1] B. Kawkabani, J.J. Simond., "Improved Modeling of Three-Phase Transformer Analysis Based on Magnetic Equivalent Circuit Diagrams And Taking Into Account Nonlinear B-H Curve", Journal Electromotion, Volume 13, Number 1, pp. 5-10, January-March 2006.

[2] Chraygane M. "Modélisation avec EMTP d'une nouvelle génération d'alimentation haute tension monophasée pour générateurs microondes à magnétrons destinés aux applications industrielles", Ph.D. dissertation, Université Ibn Zohr Agadir, Maroc, $\mathrm{n}^{\circ}$ 113/07, 2007.

[3] M. Ferfra, M. Chraygane, M. Fadel, Ould Ahmedou, "Non linear modelling of an overall new high voltage power supply for N=2 magnetrons for industrial microwave generators", Journal of Physical and Chemical News. Vol. 54: pp. 17-30, 2010 .

[4] Aguili T \& Chraygane M. "An original power generators for microwave", General Review of Electric - France, GRE 5, pp. 49-51, 1990.

[5] Chraygane M., ferfra M. \& Hlimi B. "Modeling of a high voltage power for microwave generators industrial in one magnetron", 3EI journal, Paris, France, vol. 41, pp. 37-47, 2005.

[6] M. Chraygane, M. Ferfra, B. Hlimi. "Analytic determination of the flux and the currents of the leakage flux transformer of a high voltage power supply for magnetron used for the industrial micro-waves generators 800 Watts - 2450 Mhz". Phys. Chem. News, PCN, vol. 40, pp. 51-61, 2008.

[7] Chan JH, Vladimirescu A, Gao XC, Liebmann P, Valainis J. "Non linear transformer model for circuit simulation", IEEE Transactions on Computer-Aided. 1991; 10(4).

[8] B. Bahani, A. Bouzit, M. Chraygane, M. Ferfra, A. Belhaiba, N. Elghazal M. "Modeling of a New High Voltage Power Supply for Microwave Generators with Three Magnetrons". International Journal of Electrical and Computer Engieeering (IJECE). Vol. 3, No. 2, pp. 164 170, April 2013.

[9] Ali Bouzit, Mohammed Chraygane, Naama El Ghazal, Mohammed Ferfra, M Bassoui. "Modeling of New SinglePhase High Voltage Power Supply for Industrial Microwave Generators for N=2 Magnetrons", International Journal of Electrical and Computer Engineering (IJECE), Vol. 4, No. 2, pp. 223 230, April 2014. 
[10] Bahani Boubkar, Mohammed Ferfra, Mohammed Chraygane, M. Bousseta, N. El Ghazal, A. Belhaiba." Modeling and Optimization of a New Single-Phase High Voltage Power Supply for Industrial Microwave Generators", International Review of Electrical Engineering (IREE), vol 9, $\mathrm{N}^{\mathrm{O}}$ 1, pp. 136-145, April 2014

[11] Guanghao Liu, Xiao-Bang Xu. "Improved Modeling of the Nonlinear B-H Curve and Its Application in Power Cable Analysis". IEEE Transaction on Magnetics, ; 38(4), 2002.

[12] Belhaiba A, El Ghazal N, Chraygane M. "Improved optimization of the nominal functioning of a high voltage power supply for $\mathrm{N}=2$ magnetrons for microwave generators", International Journal of Electrical and Computer Engineering, IJECE, vol 2, No5, pp. 708-716, October 2012.

[13] M. Ould. Ahmedou, M. Chraygane, M. Ferfra. "New $\pi$ Model Validation Approach to the Leakage Flux Transformer of a High Voltage Power Supply Used for Magnetron for the Industrial Micro-Waves Generators 800 Watts". International Review of Electrical Engineering (I.R.E.E.), Vol. 5. n. 3, pp. 1003-1011, May-June. 2010.

[14] Ahmedou, M. Ould. Ferfra, M. Nouri, R. Chraygane, M. "Improved $\pi$ Model of the Leakage Flux Transformer Used for Magnetrons", 2011 International Conference on Multimedia Computing and Systems -Proceedings , art. no. 5945710. 7April 2011 through 9 April 2011 Ourzazate, Morocco.

[15] Bassoui. M, Ferfra. M, Chraygane. M, Ould. Ahmedou. M, Elghazal. N and Bahani. B. " Modeling of a new high voltage power supply with three-phase character for microwaves generators with one magnetron by phase under MATLAB SIMULINK code", Journal ARPN Journal of Engineering and Applied Sciences, Vol. 9, No.12, pp. 2559-2568, December 2014.

[16] M. Bassoui, M. Ferfra, M. Chraygane, B. Bahani. 'Optimization Under Matlab Simulink Code of a Three-PhaseHV Transformer Used for Industrial Microwave Generators for One Magnetron by Phase', IEEE Mediterranean Microwave Symposium MMS'14, Marrakech 12-14 december 2014.

[17] A. Belhaiba, M. Ould. Ahmedou, M. Chraygane, M. Ferfra, N. Elghazal. "Energy balance of optimized high voltage power supply for microwaves generators used in various industrial applications", International Review on Modelling and Simulations, Vol. 5. N. 4, pp. 1460-1469, August 2012.

[18] A. Belhaiba, A. Bouzit, N. Elghaza1, M. Ferfra, M. Bousseta, M. Chraygane and B. Bahani. "Comparative Studies of Electrical Functioning of Magnetron Power Supply for One Magnetron", Journal of Engineering Science and Technology Review, Vol. 6 No.3. pp 229-238, 2013.

[19] Lütfü Sarıbulut. "A simple power factor calculation for electrical power systems", Electrical Power and Energy Systems, vol 62 pp-66-71, 2014.

[20] IEEE standard 1459 - Published on March 2010, pp. 1 - 40, Revision of IEEE Std 1459-2000. 